\title{
Age at onset and cognition in schizophrenia: meta-analysis
}

T. K. Rajji, Z. Ismail and B. H. Mulsant

\section{Background}

The relationship between cognition and age at onset of schizophrenia is largely unknown.

\section{Aims \\ To compare cognitive deficits in individuals with youth-onset and late-onset schizophrenia with those in adults with first-} episode schizophrenia.

\section{Method}

Twenty-nine databases (including EMBASE, MEDLINE and PsycINFO) were searched from 1980 to 2008. Selected publications had to include healthy controls and analyse separately individuals diagnosed with schizophrenia or a related disorder and individuals with first-episode, youthonset or late-onset schizophrenia. Descriptive and cognitive data were extracted and the latter aggregated into 22 cognitive measures. Cohen's effect size raw and weighted means of cognitive deficits were generated and compared in the three groups.

\section{Results}

Individuals with youth-onset and first-episode schizophrenia demonstrate large deficits (mean effect size $\geqslant 0.8$ ) on almost all cognitive measures. Individuals with youth-onset schizophrenia demonstrate larger deficits than those with first-episode schizophrenia on arithmetic, executive function, IQ, psychomotor speed of processing and verbal memory. In contrast, those with late-onset schizophrenia demonstrate minimal deficits on arithmetic, digit symbol coding and vocabulary, but larger ones on attention, fluency, global cognition, IQ and visuospatial construction.

\section{Conclusions}

Individuals with youth-onset schizophrenia have severe cognitive deficits, whereas those with late-onset schizophrenia have some relatively preserved cognitive functions. This finding supports the view that severity of the disease process is associated with different ages at onset. In addition, the cognitive pattern of people with late-onset schizophrenia suggests that their deficits are specific rather than solely as a result of ageing and related factors.

\section{Declaration of interest}

None.
Schizophrenia is a diverse disorder. One facet of its diversity is the age at onset. The incidence of schizophrenia peaks between 10 and 25 years for men and between 25 and 35 for women. ${ }^{1}$ Another peak, particularly among women, occurs in mid-life: about $23 \%$ of people with schizophrenia experience their first episode after the age of $40 .^{2}$ In a small group of people, schizophrenia has its onset after age 60, which has been defined as very-late-onset schizophrenia-like psychosis. ${ }^{3}$ Finally, onset of schizophrenia can occur in childhood or adolescence, typically after the age of 5 . Its prevalence is about 1 per 10000 in children, and $1-2$ per 1000 in adolescents. As in early adulthood, higher rates are reported in young males than in young females. ${ }^{4}$

DeLisi has conceptualised age at onset as a surrogate measure of severity of the disease process. ${ }^{5}$ An earlier age at onset has been associated with more severe clinical and behavioural symptoms, ${ }^{6,7}$ more social disability, ${ }^{8}$ narrower posterior brain segments ${ }^{9}$ and larger ventricles. ${ }^{10}$ Cognitive deficits in schizophrenia are core features of the illness. ${ }^{11,12}$ They are the strongest predictors of function and are considered potential targets for treatment. ${ }^{13}$ They have been well characterised, for example by Heaton et $a l,{ }^{14}$ Hoff et $a l,{ }^{15}$ and White et $a l,{ }^{16}$ and are believed to be the manifestation of the disease process affecting different brain systems. Thus, characterising the relationship between age at onset and cognitive deficits will illuminate from a cognitive perspective the unravelling of the disease process at different levels of severity. Although some studies have reported an association of earlier age at onset and more severe cognitive deficits, ${ }^{6,17-19}$ others failed to find differences in the cognitive profiles of individuals with early v. late-onset schizophrenia. ${ }^{14,20,21}$ Further, the nature of the cognitive deficits that may be associated with age at onset has varied in different studies. Considering that several of these studies have small sample sizes, and to assess whether such associations exist across the life-span, we present a meta-analysis of the literature, estimating and comparing the severity of cognitive deficits in patients with adult-onset at their first episode of schizophrenia, youth-onset (in childhood or adolescence) schizophrenia and late-onset schizophrenia. We chose to compare individuals with youth-onset or late-onset schizophrenia only to people with adult-onset schizophrenia at their first episode because individuals with youth-onset and late-onset schizophrenia are typically studied close to the onset of the illness. By contrast, in individuals with adult-onset schizophrenia who have been ill for many years, one would expect chronicity and treatment to influence cognitive deficits, thus, confounding the hypothesised specific relationships to age at onset. In this report we use the word 'schizophrenia' to refer to schizophrenia and related disorders: schizoaffective, schizophreniform, delusional disorder or very-late-onset schizophrenia-like psychosis.

\section{Method}

\section{Literature search}

A literature search of 29 databases was performed on 30 September 2008 (see Appendix for details and the search terms used). We searched back to 1980, the year of the introduction of DSM-III. ${ }^{22}$

\section{Inclusion and exclusion criteria}

Only publications that included a healthy control group were considered for this meta-analysis so that effect sizes could be calculated. Drug trials that presented pre-treatment baseline cognitive data in patients and included a healthy control group were selected. Publications were excluded if individuals with a diagnosis of schizophrenia and those with another diagnosis (e.g. bipolar disorder with psychosis) were analysed together as one sample. Similarly, publications were also excluded if individuals 
with different age at onset (i.e. childhood, adolescence, adult or late-onset) were not analysed separately or if those with adult-onset schizophrenia included people who were not in their first episode. Publications reporting on treatment trials were excluded if there were no available baseline data to compare between patients and controls. Publications reporting on the same sample were counted as a single study.

\section{Classification of studies}

If a publication met the above criteria, individuals were classified into one of three groups: first-episode schizophrenia, youth-onset schizophrenia and late-onset schizophrenia. To be classified into youth-onset schizophrenia, individuals with schizophrenia had to have a maximum age at onset of 19 years. To be classified into late-onset schizophrenia, people with schizophrenia had to have a minimum age at onset of 40 years. For any other age at onset, a selected publication was classified into the first-episode schizophrenia category provided that the study included and analysed separately those individuals with first-episode schizophrenia. Age at onset is defined differently in different studies. It is used to refer to age at first behavioural changes (e.g. DeLisi et $a l^{23}$ ), age at first manifestation of positive symptoms (e.g. White et $a l^{16}$ ) or age at first admission to hospital (e.g. Bellgrove et $a l^{24}$ ). However, these different stages have been shown to be correlated and typically within 6-18 months of each other. ${ }^{5,23,25}$ Thus, when classifying a study, we accepted the definition of age at onset as described in each individual study.

\section{Extracted variables}

After the selection and classification of a publication, the following variables were extracted and recorded: journal name, title, first author and year of publication. In addition, the following variables were recorded for patients and controls separately: number of participants and mean (s.d.) age. Some studies only provided an age threshold (e.g. 'onset before age 14'); when mean (s.d.) age at onset was provided, it was recorded and mean duration of illness was estimated based on the difference between mean age at onset and mean age. Finally, the cognitive data were recorded as follows.

\section{Cognitive measures}

The data from each cognitive test were extracted and classified into one of 22 cognitive measures (see Online supplement). The selection of these 22 measures followed a seminal quantitative review of cognitive deficits in schizophrenia. ${ }^{11}$ As noted in that review, 'organizing the myriad of neurocognitive test variables reported in the literature into a coherent classification [is] a major challenge'. We adopted the strategy employed in that review because it accounts for two opposing yet complementary approaches. The first approach is to avoid aggregating cognitive tests and to report results of individual tests. This approach is supported by the fact that most individual tests are mediated by multiple cognitive processes and tap into more than one cognitive function. Thus, aggregation into a single cognitive measure could result in misleading effect sizes that do not correspond to a specific cognitive function. This is also relevant to our review considering that in different groups (first-episode, youth-onset and late-onset schizophrenia), different cognitive tests have been used to assess particular cognitive measures. Consequently, contrasting effect sizes that correspond to these cognitive measures could be problematic. Thus, whenever possible, results of individual tests were reported separately. The second approach is to aggregate cognitive tests into a single measure based on theoretical or factor-analytical underpinnings. This approach facilitates the management of data based on various tests that tap into the same cognitive function (e.g. both California Verbal Learning Test and Rey Auditory Verbal Learning Test assess verbal memory). It also adds to the weight of effect sizes by increasing the number of individual scores contributing to a mean effect size. This is particularly relevant to our review considering the relatively small number of participants in some studies.

\section{Calculation and comparison of effect sizes}

Individual Cohen's effect sizes $\left(d_{\mathrm{i}}\right)^{26}$ were calculated for each cognitive test as the difference between the means of the schizophrenia and control groups divided by the pooled standard deviation. In some studies the groups' means and standard deviations were not available and $d_{\mathrm{i}}$-values were calculated based on the reported inferential statistics. ${ }^{27}$ Effect size raw means ( $d$-values) and their 95\% confidence intervals (CIs) were generated for each cognitive measure based on the individual $d_{\mathrm{i}}$-values aggregated in this measure. Finally, effect size weighted means (weighted $d$-values) and their standard errors (s.e.) were generated for each cognitive measure by calculating the mean of individual $d_{\mathrm{i}}$-values weighted by the inverse of their individual variance. Weighted means were also generated for age, age at onset and duration of illness. We used the $Q_{\text {between }}$ test to compare the three groups' weighted $d$-values statistically. ${ }^{28}$ When $Q_{\text {between }}$ was significant, we compared each of the weighted $d$-values of each pair separately using $Q_{\text {between }}$ with Bonferroni's adjustment. We also used two difference cut-offs to compare effect sizes qualitatively: 0.3 and 0.6. Following well-established conventions, an effect size $<0.2$ is considered small, an effect size of $0.2-0.8$ is considered medium and an effect size above 0.8 is considered large. ${ }^{26}$ Thus, a difference of 0.3 separates a small effect size (0.2) and a typical medium effect size (0.5) or a typical medium effect size (0.5) and a large effect size (0.8). A difference of 0.6 separates a small effect size and a large effect size.

\section{Results}

The 913 retrieved publications and their relevant cited and citing references were reviewed by one of the authors (T.K.R.). A total of 78 first-episode schizophrenia, 23 youth-onset schizophrenia and 9 late-onset schizophrenia publications were included in the analysis (Fig. 1; see also the Online supplement for a full list of publications included in the analysis). Age at onset was operationally defined in all of the late-onset schizophrenia and 12 of the youthonset schizophrenia publications. The remaining 11 youth-onset schizophrenia publications did not define age at onset operationally. However, in all these publications, individuals met DSM-III or later diagnostic manual criteria for schizophrenia before the age of 19. In first-episode schizophrenia publications, the first episode was always operationally defined: 61 did not define age at onset operationally.

Descriptive data of participants are reported in Table 1. The mean effect sizes ( $d$-values) of cognitive deficits, the 95\% CIs and the contributing number of studies are described in Fig. 2. Adults with first-episode schizophrenia demonstrate large deficits $(d \geqslant 0.8)$ on most cognitive tests and measures. Deficits are most pronounced on performance IQ, followed by digit symbol coding, Tower of London and similar tests, visual and verbal memory, vocabulary, arithmetic and fluency. Deficits on most of these functions also rank high among individuals with youth-onset schizophrenia. However, these people demonstrate comparably larger deficits on visuospatial construction, Stroop test and Trail Making Test B. This pattern is in contrast to that observed in 


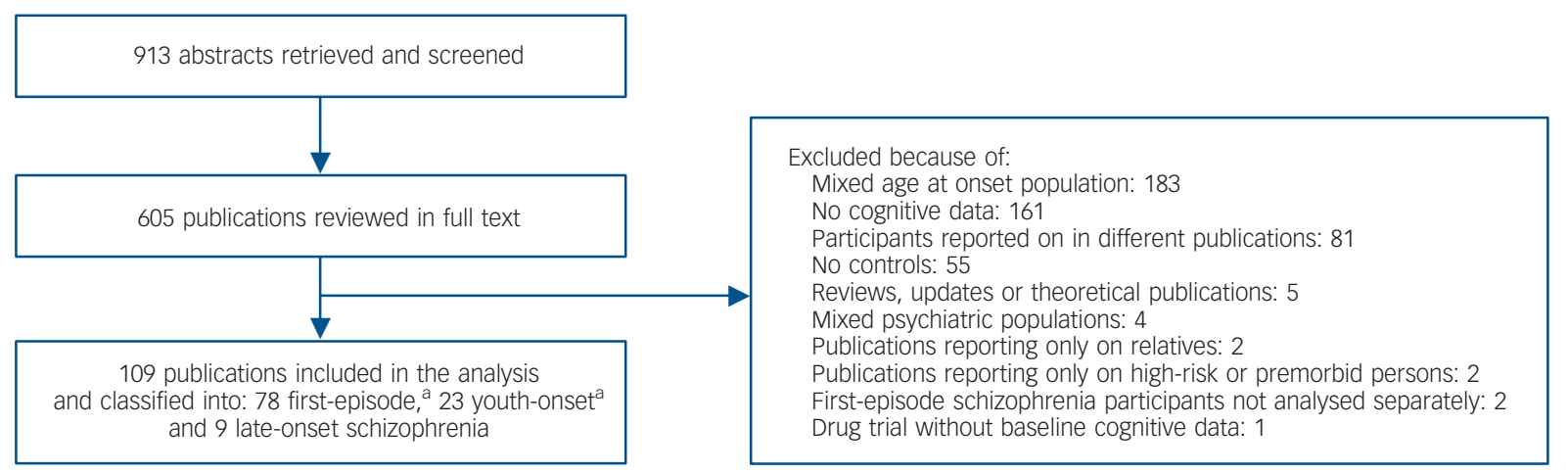

Fig. 1 Flow chart of literature review.

a. One publication contributed to both first-episode schizophrenia and youth-onset schizophrenia groups.

individuals with late-onset schizophrenia where auditory and visual attention, fluency and visuospatial construction are relatively more impaired than arithmetic, digit symbol coding, verbal memory and vocabulary.

The $Q_{\text {between }}$ test revealed statistical differences in the weighted mean effect sizes (weighted $d$-values) of the three groups for 19 of the 22 measures (there was no statistical difference for verbal general memory and verbal IQ in the three groups, and for continuous performance test between first-episode schizophrenia and youth-onset schizophrenia, Table 2). On these 19 measures, post hoc $Q_{\text {between }}$ tests with Bonferroni's adjustment showed that:

(a) individuals with youth-onset schizophrenia are more impaired than individuals with first-episode schizophrenia on full-scale IQ, psychomotor speed of processing, Trail Making Tests A and $\mathrm{B}$, verbal special memory, and Wisconsin card sorting and similar tests;

(b) individuals with youth-onset schizophrenia are more impaired than those with late-onset schizophrenia on arithmetic, digit symbol coding, vocabulary, and Wisconsin card sorting and similar tests, but less impaired on auditory and visual attention; and

(c) individuals with first-episode schizophrenia are more impaired than those with late-onset schizophrenia on digit symbol coding, but less impaired on auditory attention, fluency, full-scale IQ, global measure of cognition and visual attention.

This differential pattern of cognitive deficits is also demonstrated when comparing the magnitudes of the corresponding weighted $d$-values in first-episode, youth-onset and late-onset schizophrenia (Fig. 3 and Table 2). When comparing youth-onset schizophrenia with first-episode schizophrenia, the weighted $d$-values are within 0.3 points for 16 of the 22 cognitive measures. The weighted $d$-values are larger in the youth-onset schizophrenia than in the first-episode schizophrenia group by 0.3 points or more for four measures: arithmetic, full-scale IQ, Trail Making Test B, and Wisconsin card sorting and similar tests, and smaller for performance IQ. When comparing youth-onset schizophrenia with late-onset schizophrenia, the weighted $d$-values are within 0.3 points for 7 of the 22 measures and they differ by more than 0.3 for 11 measures. Furthermore, weighted $d$-values are larger in the late-onset schizophrenia than in the youth-onset schizophrenia group by 0.6 points or more for four measures: auditory attention, performance IQ, Stroop test and visual attention. Conversely, weighted $d$-values are smaller in the late-onset schizophrenia than in the youth-onset schizophrenia group by 0.6 points or more for four other measures: arithmetic, digit symbol coding, vocabulary and Wisconsin card sorting and similar tests. When comparing first-episode schizophrenia with late-onset schizophrenia, the weighted $d$-values are within 0.3 points for only 5 of the 22 measures and they differ by more than 0.3 for 13 measures. Furthermore, weighted $d$-values are larger in the late-onset schizophrenia than in the first-episode schizophrenia group by 0.6 points or more for six of these measures: auditory attention, fluency, full-scale IQ, global measure of cognition, Stroop test and visual attention. Conversely, weighted $d$-values are smaller in the late-onset schizophrenia than in the first-episode schizophrenia group by 0.6 points or more for three measures: arithmetic, digit symbol coding and vocabulary.

\section{Discussion}

We meta-analysed the results of 109 published studies that have compared cognitive functions of 5010 people with schizophrenia with that of healthy controls. To our knowledge, this is the first meta-analysis that addresses the relationship between age at onset and cognition in schizophrenia. When individuals were classified based on their age at onset into those with adult-onset at their first episode of schizophrenia, youth-onset schizophrenia and late-onset

\begin{tabular}{|c|c|c|c|c|}
\hline Group & Total, $n^{\mathrm{a}}$ & $\begin{array}{c}\text { Age, years: } \\
\text { weighted means (s.d.) }\end{array}$ & $\begin{array}{l}\text { Age at onset, years: } \\
\text { weighted means (s.d.) }\end{array}$ & $\begin{array}{c}\text { Duration of illness, }{ }^{\text {b }} \text { years: } \\
\text { weighted means (s.d.) }\end{array}$ \\
\hline First-episode schizophrenia & 4057 & $24.0(0.6)$ & $23.7(1.5)$ & $0.3(0.4)$ \\
\hline Youth-onset schizophrenia & 692 & $16.0(0.3)$ & $13.6(0.7)$ & $2.3(0.2)$ \\
\hline Late-onset schizophrenia & 261 & $68.4(2.6)$ & $60.7(4.2)$ & $7.7(2.3)$ \\
\hline
\end{tabular}


(a)

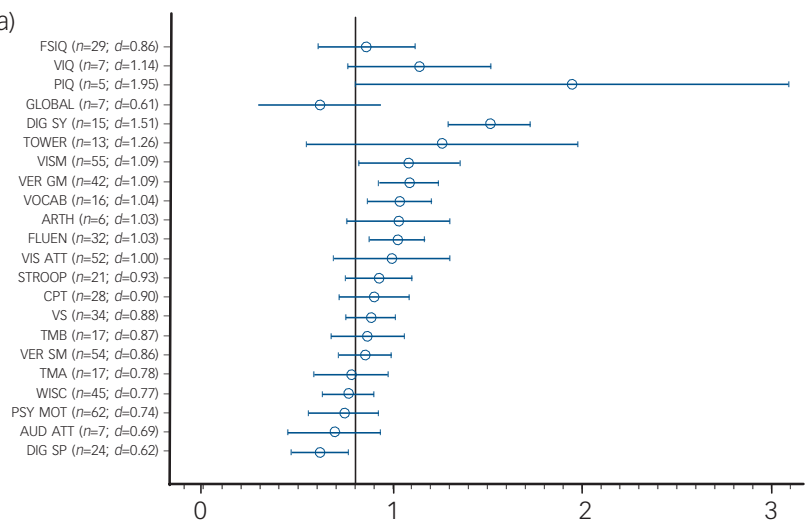

(b)

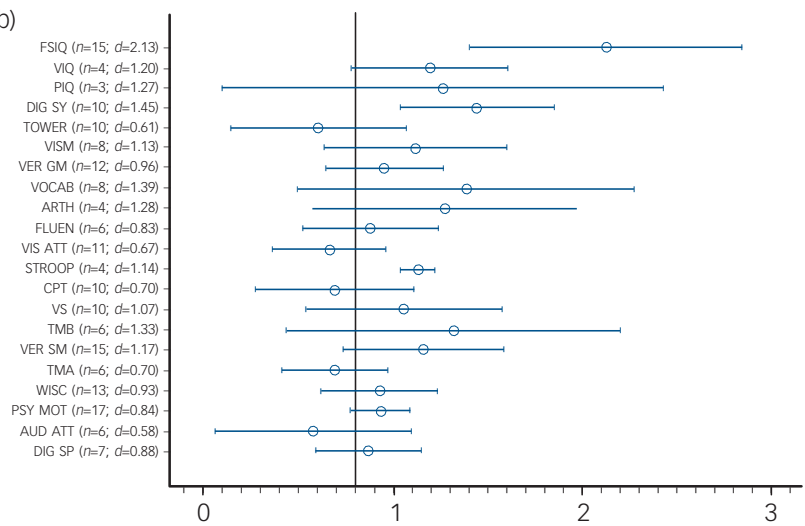

(c)

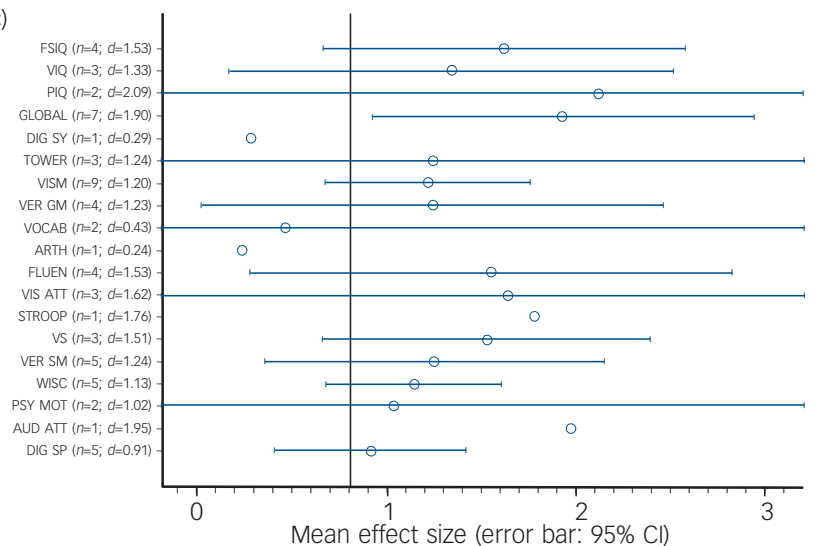

Fig. 2 The mean effect sizes of cognitive deficits of participants with first-episode schizophrenia (a), youth-onset schizophrenia (b) and late-onset schizophrenia (c).

$y$-axis: various cognitive measures. $d$, mean effect size; $n$, number of studies contributing to the mean effect size. Vertical line corresponds to effect size of 0.8 the typical threshold for large effect sizes. No studies contributed to global measure of cognition in youth-onset schizophrenia or to continuous Performance Test, Trail Making Tests A or B in late-onset schizophrenia. FSIQ, full-scale IQ; VIQ, verbal IQ; PIQ, performance IQ; GLOBAL, global measure of cognition; DIG SY, digit symbol coding; TOWER, Tower of London and similar tests; VISM, visual memory; VER GM verbal general memory; VOCAB, vocabulary; ARTH, arithmetic; FLUEN, fluency; VIS ATT, visual attention; STROOP, Stroop test: CPT, continuous performance test; VS, visuospatial construction: TMB, trail making test B; VER SM, verbal special VS, visuospatial construction; $A M B$, trall maki, CPT, cont B; VER SM, verbal special memory; TMA, trail making test A; WISC, Wisconsin card sorting and similar tests;
PSY MOT, psychomotor speed of processing; AUD ATT, auditory attention; DIG SP, digit span.

schizophrenia, the three groups demonstrated strikingly different patterns of cognitive deficits.

This meta-analysis has a number of limitations. First, although the classification of different age at onset is based on current expert opinion, it is to a large extent arbitrary. For example, some consider childhood-onset schizophrenia to be merely a more severe form of, and on a clinical and neurobiological continuum with, adult-onset schizophrenia. ${ }^{29,30}$ The results of our analysis are consistent with this view. In contrast, the inclusion of very-late-onset schizophrenia-like psychosis under the broader category of late-onset schizophrenia is controversial because very-late-onset schizophrenia-like psychosis appears to have less genetic underpinnings, to be associated with more sensory deficits, and to have different phenomenology. ${ }^{3}$

Second, as stated above, we based our classification of age at onset on the definition used in each individual study even though these definitions differed. We believe this approach is sound because these different definitions have been shown to yield age at onsets that are highly correlated and within a few months of each other. ${ }^{5,23,25}$ Furthermore, it would not be possible to apply retrospectively a single definition of age at onset to a large number of samples characterised with different variables.

Third, the number of studies of late-onset schizophrenia compared with those of first-episode schizophrenia or youth-onset schizophrenia is small. This limitation impedes the consideration in the analysis of factors such as duration of illness, education level, premorbid intellectual abilities or comorbid diseases.

Fourth, some cognitive tests that may not be equivalent were aggregated into a single cognitive measure. However, such aggregation was based on theoretical or factor-analytical grounds. It also enabled the capture of a large quantity of data generated by related cognitive tests and the reduction of the number of comparisons.

Finally, we used control groups of the different studies to generate the effect sizes. The cognitive profiles of these various control groups were naturally different. However, the normal controls were typically matched to the participants with schizophrenia, supporting the validity of comparing effect sizes.

Notwithstanding these limitations, our results extend the large literature on cognitive deficits in schizophrenia, in particular five recent meta-analyse ${ }^{11,31-34}$ and they need to be considered in this context. The diversity of individuals with schizophrenia is likely to be a reflection of multiple pathological processes. Understanding this diversity is critical to the development of personalised treatment interventions. Age at onset and cognition of individuals with schizophrenia are two aspects of the illness where diversity manifests itself. Age at onset can range from childhood to very late in life. Cognitive function can vary from normality ${ }^{35}$ to severe impairment.

Our analysis reports large cognitive deficits in most cognitive measures in first-episode schizophrenia. The magnitudes of these deficits are consistent with the magnitudes reported in other meta-analyses. However, the deficits we report in verbal memory, and to a lesser extent executive function and attention, are smaller than those reported in other meta-analyses. ${ }^{11,31,34,36}$ In these other analyses, participants were not restricted to those presenting during their first episode. Thus, the larger deficits reported in these previous analyses could reflect the harmful impact of chronicity of psychosis on cognition, especially on verbal memory. Psychosis in another neuropsychiatric disorder (Alzheimer's disease) has also been associated with acceleration of cognitive decline. $^{37,38}$ The potential impact of chronicity on cognition emphasises the importance of age at onset and its corollary, duration of illness.

Individuals with youth-onset schizophrenia have cognitive deficits that are larger than those with first-episode schizophrenia in arithmetic, executive function, full-scale IQ, psychomotor speed of processing and verbal memory. In contrast, they have deficits that are comparable in magnitudes with those in firstepisode schizophrenia in the other measures. These findings are in agreement with Tuulio-Henriksson et al ${ }^{19}$ who reported an 
Table 2 Cognitive deficits effect sizes: weighted mean (s.e)

\begin{tabular}{|c|c|c|c|c|c|}
\hline Cognitive measure & $\begin{array}{l}\text { First-episode } \\
\text { schizophrenia } \\
\text { (FES) }\end{array}$ & $\begin{array}{l}\text { Youth-onset } \\
\text { schizophrenia } \\
\text { (YOS) }\end{array}$ & $\begin{array}{l}\text { Late-onset } \\
\text { schizophrenia } \\
\text { (LOS) }\end{array}$ & $Q_{\text {between }}$ & FES v. YOS v. $\operatorname{LOS}^{\mathrm{a}}$ \\
\hline Full-scale IQ & $0.89(0.04)$ & $1.77(0.07)$ & $1.61(0.15)$ & $121.64^{* * *}$ & $\mathrm{FES}<\mathrm{YOS}, \mathrm{FES}<\mathrm{LOS}, \mathrm{YOS}=\mathrm{LOS}$ \\
\hline Verbal IQ & $1.31(0.08)$ & $1.19(0.13)$ & $1.34(0.16)$ & 0.75 & - \\
\hline Performance IQ & $1.73(0.09)$ & $1.25(0.15)$ & $2.07(0.23)$ & $11.75^{\star \star}$ & $F E S=Y O S=L O S$ \\
\hline Global measure of cognition & $0.67(0.10)$ & - & $1.67(0.11)$ & $45.74^{* * *}$ & FES $<$ LOS \\
\hline Digit symbol coding & $1.46(0.05)$ & $1.46(0.09)$ & $0.29(0.22)$ & $27.18^{* * *}$ & $\mathrm{FES}=\mathrm{YOS}, \mathrm{LOS}<\mathrm{FES}, \mathrm{LOS}<\mathrm{YOS}$ \\
\hline Tower of London and similar tests & $0.78(0.05)$ & $0.57(0.08)$ & $0.97(0.15)$ & $8.18^{*}$ & $\mathrm{FES}=Y O S=L O S$ \\
\hline Visual memory & $0.85(0.03)$ & $0.95(0.10)$ & $1.12(0.09)$ & $9.46 * *$ & $\mathrm{FES}=\mathrm{YOS}=\mathrm{LOS}$ \\
\hline Verbal general memory & $1.03(0.03)$ & $0.98(0.07)$ & $1.11(0.13)$ & 0.86 & - \\
\hline Vocabulary & $1.02(0.05)$ & $1.18(0.11)$ & $0.42(0.19)$ & $11.76^{* *}$ & FES=YOS, FES=LOS, LOS $<$ YOS \\
\hline Arithmetic & $0.99(0.07)$ & $1.37(0.12)$ & $0.24(0.26)$ & $17.74^{* * *}$ & $F E S=Y O S, F E S=L O S, L O S<Y O S$ \\
\hline Fluency & $0.87(0.03)$ & $0.96(0.10)$ & $1.47(0.14)$ & $17.50^{* * *}$ & $F E S=Y O S, F E S<L O S, Y O S=L O S$ \\
\hline Visual attention & $0.72(0.03)$ & $0.66(0.08)$ & $1.51(0.15)$ & $26.72^{* * *}$ & FES $=Y O S$, FES $<L O S$, YOS $<$ LOS \\
\hline Stroop test & $0.86(0.04)$ & $1.14(0.13)$ & $1.76(0.27)$ & 14.20 ** & $\mathrm{FES}=\mathrm{YOS}=\mathrm{LOS}$ \\
\hline Continuous Performance Test & $0.83(0.04)$ & $0.73(0.08)$ & - & 1.17 & - \\
\hline Visuospatial construction & $0.83(0.03)$ & $0.98(0.08)$ & $1.41(0.18)$ & $12.97 * *$ & $\mathrm{FES}=\mathrm{YOS}=\mathrm{LOS}$ \\
\hline Trail making test $\mathrm{B}$ & $0.77(0.05)$ & $1.12(0.10)$ & - & $9.82 * *$ & FES $<$ YOS \\
\hline Verbal special memory & $0.94(0.03)$ & $1.18(0.06)$ & $1.20(0.12)$ & $15.04^{* * *}$ & $\mathrm{FES}<\mathrm{YOS}, \mathrm{FES}=\mathrm{LOS}, \mathrm{YOS}=\mathrm{LOS}$ \\
\hline Trail making test $\mathrm{A}$ & $0.66(0.04)$ & $0.70(0.10)$ & - & $8.82^{*}$ & $\mathrm{FES}<\mathrm{YOS}$ \\
\hline Wisconsin card sorting and similar tests & $0.76(0.03)$ & $2.00(0.08)$ & $1.13(0.12)$ & $231.41 * * *$ & $\mathrm{FES}<\mathrm{YOS}, \mathrm{FES}=\mathrm{LOS}, \mathrm{LOS}<\mathrm{YOS}$ \\
\hline Psychomotor speed of processing & $0.65(0.02)$ & $0.92(0.06)$ & $1.01(0.21)$ & $19.68^{* * *}$ & $\mathrm{FES}<\mathrm{YOS}, \mathrm{FES}=\mathrm{LOS}, \mathrm{YOS}=\mathrm{LOS}$ \\
\hline Auditory attention & $0.61(0.08)$ & $0.53(0.12)$ & $1.95(0.27)$ & $23.47^{* * *}$ & $\mathrm{FES}=\mathrm{YOS}, \mathrm{FES}<\mathrm{LOS}, \mathrm{YOS}<\mathrm{LOS}$ \\
\hline Digit span & $0.64(0.04)$ & $0.85(0.10)$ & $0.87(0.12)$ & $6.69^{*}$ & $F E S=Y O S=L O S$ \\
\hline
\end{tabular}

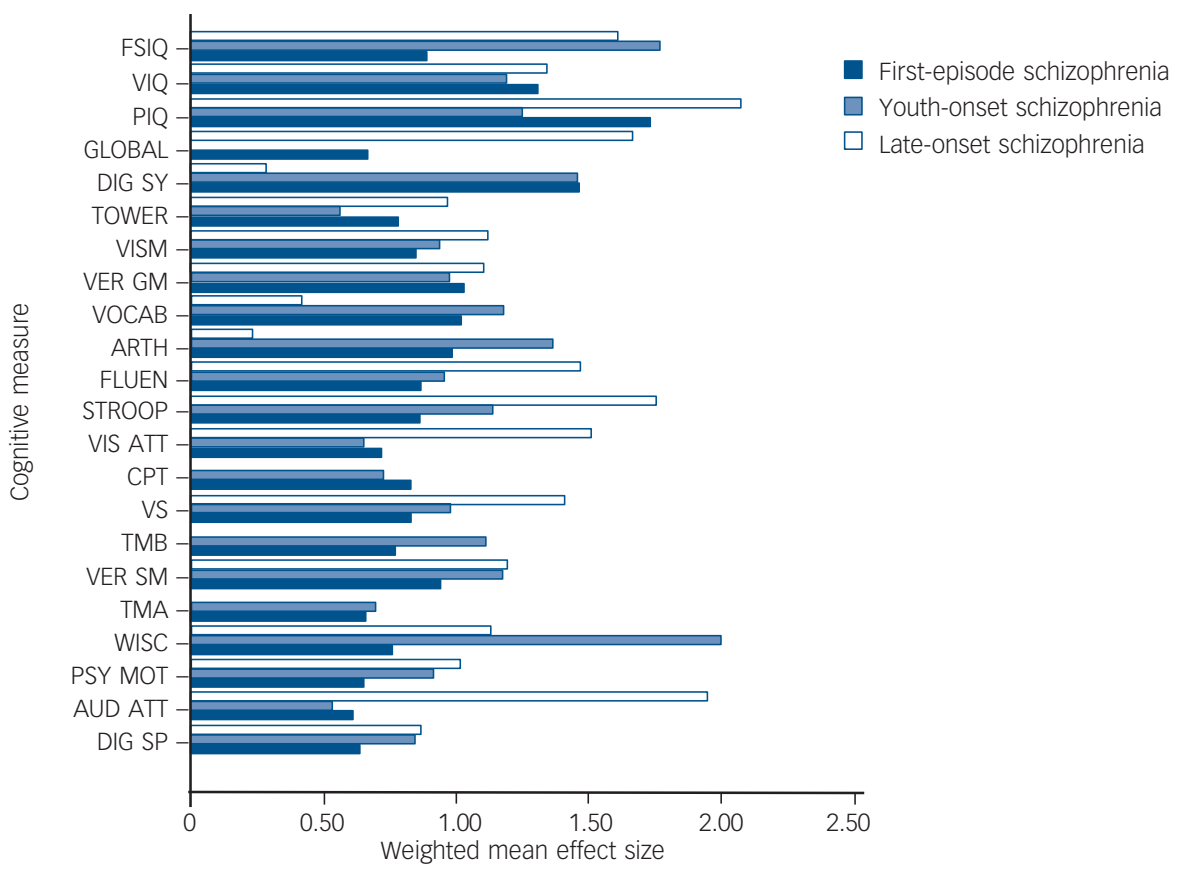

Fig. 3 Qualitative comparison of weighted mean effect sizes (weighted $d$-values) of cognitive deficits of participants with first-episode, youth-onset schizophrenia and late-onset schizophrenia compared with healthy controls.

FSIQ, full-scale IQ; VIQ, verbal IQ; PIQ, performance IQ; GLOBAL, global measure of cognition; DIG SY, digit symbol coding; TOWER, Tower of London and similar tests; VISM, visual memory; VER GM, verbal general memory; VOCAB, vocabulary; ARTH, arithmetic; FLUEN, fluency; VIS ATT, visual attention; STROOP, Stroop test; CPT, continuous performance test; VS, visuospatial construction; TMB, trail making test B; VER SM, verbal special memory; TMA, trail making test A; WISC, Wisconsin card sorting and similar tests; PSY MOT, psychomotor speed of processing; AUD ATT, auditory attention; DIG SP, digit span. 
association between younger age at onset (range 13-44 years) and larger deficits in verbal learning and memory, and semantic clustering, an executive function, but an absence of such an association in attention (verbal and visual), visuospatial function and vocabulary. Basso et $a l^{39}$ also reported more severe deficits in executive function and memory in individuals with adolescentonset schizophrenia (age at onset $<21$ ) compared with those with adult-onset schizophrenia (age at onset $>24$ ). However, our findings are in conflict with the absence of an association between age at onset and deficit in psychomotor speed of processing reported by Tuulio-Henriksson et al. ${ }^{19}$ This discrepancy could be because they included participants with chronic schizophrenia and excluded those with age at onset less than 13 years. White et $a l^{16}$ did report a more severe impairment in psychomotor speed in participants with adolescent-onset schizophrenia (range 12-19 years) when compared with adults with first-episode schizophrenia. Further, Hoff et al's ${ }^{6}$ study that included participants with chronic schizophrenia but with age at onset as young as 7 (range 7-29 years) also found an association between younger age at onset and larger deficits on Trail Making Test B and psychomotor speed of processing, in agreement with our findings. However, in contrast with our findings, Hoff $e t a l^{6}$ did not find such an association in verbal memory or Wisconsin card sorting test. This is probably because of their small sample size, hence the advantage of a meta-analysis. Overall, our comparison of individuals with youth-onset schizophrenia or first-episode schizophrenia is consistent with the conceptualisation of age at onset as a surrogate measure of severity of disease process: an earlier onset reflects a more severe illness. In our analysis, this is the case even though individuals with youth-onset schizophrenia had a brief duration of illness (2.3 years at time of testing on average). These larger deficits suggest a high disease burden consistent with the high rate of chromosomal abnormalities, higher familial rates of schizophrenia-spectrum disorders, ${ }^{30,40}$ and early and progressive cortical grey matter loss observed in the frontal lobes of individuals with childhood-onset schizophrenia (e.g. Vidal et $a l^{41}$ ).

Also consistent with this conceptualisation, individuals with late-onset schizophrenia seem to have some relatively preserved cognitive functions such as arithmetic, digit symbol coding and vocabulary. This is consistent with a less severe disease process, even though the duration of their illness is longer than the duration of those with youth-onset schizophrenia ( 7.7 v. 2.3 years on average at the time of testing). Assessing semantic organisation, Paulsen et $a l^{18}$ reported that individuals with late-onset schizophrenia (age at onset $>45$ years) were preserved compared with people with an early onset. In contrast, our analysis reveals that participants with late-onset schizophrenia are severely impaired on measures of auditory and visual attention, fluency, global measure of cognition, IQ and visuospatial construction, and more so than individuals with youth-onset schizophrenia or first-episode schizophrenia on most of these measures. These findings are in conflict with those by the University of California, San Diego group ${ }^{14,20}$ and Sachdev et $a l^{21}$ who showed no difference between participants with late-onset schizophrenia (age at onset $>45) ; ;^{14,20}$ age at onset $>49^{21}$ and early-onset (age at onset $\leqslant 45 ;^{14,20}$ age at onset $\left.<35\right)^{21}$ schizophrenia on any cognitive measure. A number of factors could have resulted in these discrepancies. First and foremost, the absence of any detected differences may be a result of the small sample sizes, a limitation of any single study of late-onset schizophrenia. This limitation highlights the contribution of a meta-analysis. Second, in the University of California, San Diego studies, participants with early-onset schizophrenia included some people with age at onset as late as 45 . Such a high range may have prevented the detection of differences between early-onset schizophrenia and late-onset schizophrenia that we observed in our analysis. In fact, when the University of California, San Diego group assessed the relationship between cognition and age at onset (range 6-64 years) as a continuous variable in the same participants, ${ }^{17}$ younger age at onset was associated with a more severe deficit in executive function in agreement with our findings. Third, in the University of California, San Diego and Sachdev et al ${ }^{21}$ studies, individuals with early-onset schizophrenia had significantly longer duration of illness than those with late-onset schizophrenia (e.g. about 30 years for early-onset $v .6$ years for late-onset schizophrenia in the study by Lee \& Park). ${ }^{36}$ Thus, the effect of chronicity on individuals with an early onset could have contributed to the absence of differences between the two groups. In the same vein, in our analysis, the relatively longer duration of illness in individuals with late-onset schizophrenia as compared with those with youth-onset or first-episode schizophrenia may be contributing to the observed larger deficits on some measures.

The large impairment in attention, fluency and visuospatial construction function in participants with late-onset schizophrenia compared with age-matched healthy controls suggests specific deficits in these cognitive functions in the context of minimal impairment in arithmetic, digit symbol coding and vocabulary. These large deficits could be underlying the similarly observed large impairment in global cognition and IQ. The small deficit on digit symbol coding is of particular interest. Performance on this task is thought to depend on non-specific and ubiquitous neurological processes ${ }^{42}$ and correlates with broad prefrontal and temporal grey matter volumes. ${ }^{43}$ Thus, a lesser impairment on this task suggests specific rather than generalised cognitive deficits in late-onset schizophrenia. However, the number of studies contributing to these effect sizes is small (e.g. only one study contributed to arithmetic, auditory attention and digit symbol coding in late-onset schizophrenia). Further, performance on a specific task is likely to involve multiple cognitive mechanisms. ${ }^{44}$ Thus, a more impaired performance in visuospatial construction than in digit symbol coding, for example, does not necessarily imply that the disease process is specific to a single cognitive mechanism underlying visuospatial construction. It could merely suggest that some of several cognitive mechanisms underlying digit symbol coding are less affected by the disease process than some of those underlying visuospatial construction. Such a less pervasive disease process results in the relative preservation of a particular cognitive function compared with another.

Another possible model is that the disease-related cognitive deficits observed in late-onset schizophrenia could be as a result of an interaction between the disease process and ageing: these deficits could have been present but less prominent prior to the onset of the clinical syndrome. Then, the ageing process and associated allostatic factors such as cerebrovascular disease, diabetes and hypertension, could amplify these deficits resulting in larger deficits compared with younger people with first-episode schizophrenia, even after correcting for the pure effect of ageing observed in older controls.

Longitudinal and controlled studies will be necessary to address these questions of specific deficits $v$. preserved cognitive functions, and to advance our understanding of the relationship between the disease process underlying schizophrenia, cognition, age at onset, duration of illness, ageing and associated allostatic factors. Such studies would need to target individuals at their first episode or in their prodromal phase, or high-risk people across the life cycle. A more feasible study that would focus on older individuals and controls and follow them longitudinally could disentangle the cognitive deficits or changes that are a result of the illness from those resulting from normal ageing or certain allostatic factors. Characterising such pathological relationships 
will help towards the development of personalised interventions to enhance cognition or prevent its decline.

T. K. Rajji, MD, FRCPC, z. Ismail, MD, FRCPC, B. H. Mulsant, MD, MS, FRCPC, Department of Psychiatry, University of Toronto and Geriatric Mental Health Program, Centre for Addiction and Mental Health, Toronto, Canada

Correspondence: B. H. Mulsant, Geriatric Mental Health Program, $\mathrm{CAMH}_{4}$ 1001 Queen Street West, Toronto, Ontario M6J 1H4, Canada. Email: Benoit_Mulsant@camh.net

First received 20 Oct 2008, final submission 17 Jan 2009, accepted 3 Mar 2009

\section{Funding}

T.K.R. is supported by the Centre for Addiction and Mental Health (CAMH) and the Canadian Institutes of Health Research (CIHR180087).

\section{Acknowledgements}

We thank Dr Dilip V. Jeste for his encouragement to conduct this review.

\section{Appendix}

\section{Literature search: databases and search terms}

A literature search of 29 databases was performed using CINAHL, EMBASE, and the multi-database search engine, scholars Portal that includes MEDLINE, PSycARTICLES, PSycINFO, Psychology: A SAGE Full-Text Collection, and the following: AGRICOLA, Aqualine, ASFA: Aquatic Sciences and Fisheries Abstracts, Biological and Agricultural Index Biological Sciences, Biology Digest, Biotechnology and Bioengineering Abstracts, Compendex, Conference Papers Index, Digital Dissertations, E-Journals, EIS: Digests of Environmental Impact Statements, Environmenta Sciences and Pollution Mgmt, General Science Abstracts, Geobase GeoRef, GeoRef In Process, Meteorological \& Geoastrophysical Abstracts Oceanic Abstracts, Pharmaceutical News Index, Physical Education Index Plant Science, Science Citation Index Expanded, Scopus Natural Sciences, TOXLINE and Zoological Record Plus.

The following search terms were used: schizophrenia, schizoaffective, psychotic disorder, age of onset, age at onset, childhood onset, adolescent onset, late onset, first episode, cognition, neuropsychology, memory, learning, Wechsler, complex figure, face recognition, spatia perception, line orientation, Purdue, motor dexterity, finger tapping, moto disorder, Stroop test, digit span, continuous performance test, backward masking, trails, trail making, Wisconsin card sorting test, IQ, vocabulary, block design, word fluency, token, comprehension, affect recognition, dichotic listening.

\section{References}

1 Buchanan RW, Carpenter WT. Concept of schizophrenia. In Kaplan \& Sadock's Comprehensive Textbook of Psychiatry (8th edn) (eds BJ Sadock \& VA Sadock): 1329. Lippincott Williams \& Wilkins, 2005.

2 Harris MJ, Jeste DV. Late-onset schizophrenia - an overview. Schizophr Bull 1988: 14: 39-55.

3 Howard R, Rabins PV, Seeman MV, Jeste DV. Late-onset schizophrenia and very-late-onset schizophrenia-like psychosis: an international consensus. Am J Psychiatry 2000; 157: 172-8.

4 McClennan JM. Early-onset schizophrenia. In Kaplan \& Sadock's Comprehensive Textbook of Psychiatry (8th edn) (eds BJ Sadock \& VA Sadock): 3307. Lippincott Williams \& Wilkins, 2005.

5 Delisi LE. The significance of age of onset for schizophrenia. Schizophr Bull 1992: 18: 209-15.

6 Hoff AL, Harris D, Faustman WO, Beal M, DeVilliers D, Mone RD, et al. A neuropsychological study of early onset schizophrenia. Schizophr Res 1996; 20: $21-8$.

7 Johnstone EC, Owens DGC, Bydder GM, Colter N, Crow TJ, Frith CD. The spectrum of structural brain changes in schizophrenia: age of onset as a predictor of cognitive and clinical impairments and their cerebral correlates. Psychol Med 1989; 19: 91-103.
8 Eggers C, Bunk D. The long-term course of childhood-onset schizophrenia: a 42-year followup. Schizophr Bull 1997; 23: 105-17.

9 Crow TJ, Colter N, Frith CD, Johnstone EC, Owens DGC. Developmental arrest of cerebral asymmetries in early onset schizophrenia. Psychiatry Res 1989; 29: 247-53.

10 Raz S, Raz N. Structural brain abnormalities in the major psychoses - a quantitative review of the evidence from computerized imaging. Psychol Bull 1990; 108: 93-108.

11 Heinrichs RW, Zakzanis KK. Neurocognitive deficit in schizophrenia: a quantitative review of the evidence. Neuropsychology 1998; 12: 426-45.

12 Rajji TK, Mulsant BH. Nature and course of cognitive function in late-life schizophrenia: a systematic review. Schizophr Res 2008; 102: 122-40.

13 Green MF, Kern RS, Heaton RK. Longitudinal studies of cognition and functional outcome in schizophrenia: implications for MATRICS. Schizophr Res 2004; 72: 41-51.

14 Heaton R, Paulsen JS, McAdams LA, Kuck J, Zisook S, Braff D, et al. Neuropsychological deficits in schizophrenics. Relationship to age, chronicity, and dementia. Arch Gen Psychiatry 1994; 51: 469-76.

15 Hoff AL, Sakuma M, Wieneke M, Horon R, Kushner M, Delisi LE. Longitudinal neuropsychological follow-up study of patients with first-episode schizophrenia. Am J Psychiatry 1999; 156: 1336-41.

16 White T, Ho BC, Ward J, O'Leary D, Andreasen NC. Neuropsychological performance in first-episode adolescents with schizophrenia: a comparison with first-episode adults and adolescent control subjects. Biol Psychiatry 2006; 60: 463-71.

17 Jeste DV, McAdams LA, Palmer BW, Braff D, Jernigan TL, Paulsen JS, et al. Relationship of neuropsychological and MRI measures to age of onset of schizophrenia. Acta Psychiatr Scand 1998; 98: 156-64.

18 Paulsen JS, Romero R, Chan A, Davis AV, Heaton RK, Jeste DV. Impairment of the semantic network in schizophrenia. In 23rd Annual Meeting of the International-Neuropsychological-Society: 08-11. Elsevier Science Ireland, 1995

19 Tuulio-Henriksson A, Partonen T, Suviusaari J, Haukka J, Lönnqvist J. Age at onset and cognitive functioning in schizophrenia. Br J Psychiatry 2004; 185 215-9.

20 Jeste DV, Harris MJ, Krull A, Kuck J, McAdams LA, Heaton R. Clinical and neuropsychological characteristics of patients with late-onset schizophrenia. Am J Psychiatry 1995; 152: 722-30.

21 Sachdev $\mathrm{P}$, Brodaty $\mathrm{H}$, Rose N, Cathcart S. Schizophrenia with onset after age 50 years. 2: Neurological, neuropsychological and MRI investigation. Br J Psychiatry 1999; 175: 416-21.

22 American Psychiatric Association. Diagnostic and Statistical Manual of Mental Disorders (3rd edn) (DSM-III). APA, 1980.

23 DeLisi LE, Hoff AL, Schwartz JE, Shields GW, Halthore SN, Gupta SM, et al Brain morphology in 1st-episode schizophrenic-like psychotic patients: a quantitative magnetic resonance imaging study. Biol Psychiatry 1991; 29: 159-75

24 Bellgrove MA, Collinson S, Mattingley JB, Pantelis C, Fitzgerald PB, James AC, et al. Attenuation of perceptual asymmetries in patients with early-onset schizophrenia: evidence in favour of reduced hemispheric differentiation in schizophrenia? Laterality 2004; 9: 79-91.

25 Delisi LE, Goldin LR, Maxwell ME, Kazuba DM, Gershon ES. Clinical features of illness in siblings with schizophrenia or schizoaffective disorder. Arch Gen Psychiatry 1987; 44: 891-6.

26 Cohen J. Statistical Power Analysis for the Behavioral Sciences, (2nd edn). Academic Press, 1988.

27 Wolf FM. Meta-Analysis: Quantitative Methods for Research Synthesis. Sage, 1986.

28 Lipsey MW, Wilson DB. Practical Meta-Analysis. Sage, 2000.

29 Nicolson R, Rapoport JL. Childhood-onset schizophrenia: rare but worth studying. Biol Psychiatry 1999; 46: 1418-28.

30 Rapoport JL, Addington AM, Frangou S, Psych M. The neurodevelopmental model of schizophrenia: update 2005. Mol Psychiatry 2005; 10: 434-49.

31 Aleman A, Hijman R, de Haan EHF, Kahn RS. Memory impairment in schizophrenia: a meta-analysis. Am J Psychiatry 1999; 156: 1358-66.

32 Fioravanti M, Carlone $\mathrm{O}$, Vitale $\mathrm{B}$, Cinti ME, Clare L. A meta-analysis of cognitive deficits in adults with a diagnosis of schizophrenia. Neuropsychol Rev 2005; 15: 73-95.

33 Henry JD, Crawford JR. A meta-analytic review of verbal fluency deficits in schizophrenia relative to other neurocognitive deficits. Cogn Neuropsychiatry 2005; 10: 1-33.

34 Laws KR. A meta-analytic review of Wisconsin Card Sort studies in schizophrenia: general intellectual deficit in disguise? Cogn Neuropsychiatry 1999; 4: 1-30. 
35 Palmer BW, Heaton RK, Paulsen JS, Kuck J, Braff D, Harris MJ, et al. Is it possible to be schizophrenic yet neuropsychologically normal? Neuropsychology 1997; 11: 437-46.

36 Lee JH, Park S. Working memory impairments in schizophrenia: a metaanalysis. J Abnorm Psychol 2005; 114: 599-611.

37 Drevets WC, Rubin EH. Psychotic symptoms and the longitudinal course of senile dementia of the Alzheimer type. Biol Psychiatry 1989; 25: 39-48.

38 Lopez OL, Wisniewski SR, Becker JT, Boller F, DeKosky ST. Psychiatric medication and abnormal behavior as predictors of progression in probable Alzheimer disease. Arch Neurol 1999; 56: 1266-72.

39 Basso MR, Nasrallah HA, Olson SC, Bornstein RA. Cognitive deficits distinguish patients with adolescent- and adult-onset schizophrenia. Neuropsychiatr Neuropsychol Behav Neurol 1997; 10: 107-12.
40 Nicolson R, Brookner FB, Lenane M, Gochman P, Ingraham L, Egan MF, et al. Parental schizophrenia spectrum disorders in childhood-onset and adultonset schizophrenia. Am J Psychiatry 2003; 160: 490-5.

41 Vidal CN, Rapoport JL, Hayashi KM, Geaga JA, Sui YH, McLemore LE, et al. Dynamically spreading frontal and cingulate deficits mapped in adolescents with schizophrenia. Arch Gen Psychiatry 2006; 63: 25-34.

42 Dickinson D, Ramsey ME, Gold JM. Overlooking the obvious: a meta-analytic comparison of digit symbol coding tasks and other cognitive measures in schizophrenia. Arch Gen Psychiatry 2007; 64: 532-42.

43 Sanfilipo M, Lafargue T, Rusinek H, Arena L, Loneragan C, Lautin A, et al. Cognitive performance in schizophrenia: relationship to regional brain volumes and psychiatric symptoms. Psychiatry Res 2002; 116: 1-23.

44 Keefe RSE. The contribution of neuropsychology to psychiatry. Am J Psychiatry 1995; 152: 6-15

\section{Psychiatry in the Old Testament}

\section{The essa zarah, the strange women of the Book of Proverbs}

\section{George Stein}

The word zar means strange, but it originally referred to being married to someone outside the tribe, beyond the geographical border. More recently, essa zarah has been translated as a loose woman. She is sexually provocative ( $7: 10$ 'Then a woman comes towards him decked out like a prostitute, wily of heart') and quite dramatic (11 'She is loud and wayward'). Here the Hebrew word for loud is homiyyah which also means 'clamorous, noisy, or boisterous'.

She also displays an inner restlessness and is desperate for male company and affairs: '11 Her feet do not stay at home; 12 now in the street, now in the square and at every corner she lies in wait'.

She is impulsive and is visibly angry in her face: 13 'She seizes him and kisses him and with an impudent face she says to him - (she then goes on to seduce the man) - 17 'I have perfumed my bed with myrrh aloes, and cinnamon,' 18 'Come let us take our fill of love until morning: let us delight ourselves in love until morning'. 19 'For my husband is not at home; he has gone on a long journey'. Adultery in those days was punishable by death and having repeated affairs would have been a highly risky type of behaviour.

Though seductive, her relationships are brief and the love soon becomes bitter: 5:3 'For the lips of the strange woman drip honey, for her speech is smoother than oil'. 4 'But in the end she is bitter as wormwood, sharp as a two edged sword'.

She leads a chaotic life and possibly has some kind of identity disturbance: 5:6 'She does not keep straight to the path of life, her ways wander, and she does not know it'.

This seems to be quite a good description of borderline personality disorder; the woman displays many DSM-IV borderline and histrionic features. Other scholars suggest she may be an allegorical figure, a foreign prostitute, a diatribe against inter-marriage, or a mythological femme fatale. 